\title{
Consumer Behaviour towards Honey Products in Western Australia
}

\section{Extended Abstract}

\section{Purpose}

This paper explores the factors impacting and influencing the consumer's decision to purchase honey in a retail store.

\section{Design}

Data is collected from shopping mall intercepts in Perth, Western Australia using a structured questionnaire. Factor analysis is used to identify the principal components which most influence the consumer's decision to purchase. On the basis of the ways in which honey is consumed within the household, cluster analysis is utilised to group the respondents into meaningful segments.

\section{Findings}

In Perth, Western Australia, honey is primarily consumed as a spread or a sweetener on breakfast cereals and porridge. However, honey is also used as a marinade, in cakes and cookies and as a beverage. According to the way in which honey is consumed in the household, five clusters are identified. In purchasing honey from a retail store, principal component analysis reveals three factors which were most influential in the consumer's decision to purchase: brand reputation, origin and value for money. Ethnicity was found to have a significant influence on the way in which honey was consumed in the household and the importance of the three principal components extracted.

\section{Originality/value}

This is one of the few studies that find a segment difference between Anglo Saxon and Asian consumers of honey. 


\title{
Consumer Behaviour towards Honey Products in Western Australia
}

\begin{abstract}
In Perth, Western Australia, honey is primarily consumed as a spread or a sweetener on breakfast cereals and porridge. However, honey is also used as a marinade, in cakes and cookies and as a beverage. According to the way in which honey is consumed in the household, five clusters are identified. In purchasing honey from a retail store, principal component analysis reveals three factors which were most influential in the consumer's decision to purchase: brand reputation, origin and value for money. Ethnicity was found to have a significant influence on the way in which honey was consumed in the household and the importance of the three principal components extracted.
\end{abstract}

Key Words: market segmentation, cluster analysis, Asia

\section{Introduction}

Honey has been in use throughout the world across many millennia. Honey's popularity is evident from the variety of uses throughout history: honey is not only used as a sweetener, but also as a natural beauty agent and has been employed in some cultures for its medicinal attributes (National Honey Board).

Honey is consumed all over the world. The largest consumers are the United States with around 153,000 tonnes, China with around 123,000 tonnes and Germany which consumes approximately 90,000 tonnes per annum (AAFRD, 2005). As consumption has been relatively stable over the last five years, climate and quality have been the key factors driving the world market. The restrictions placed on China and Argentina by the US in recent years and adverse weather conditions have affected a number of large honey-producing countries such as Mexico, Australia and Canada (CIE, 2005). In Australia, there are around 9,600 registered beekeepers with approximately 500,000 hives. The gross value of honey production is around AUD 60 million per annum. Production averages 30,000 tonnes per annum, one third of which is exported. Key markets are the United Kingdom, Indonesia and other South East Asian nations, North America and Saudi Arabia. New South Wales is the largest producer (41\%), with Victoria producing 19\%, Queensland 15\%, South Australia 13\%, Western Australia 8\% and Tasmania 4\% (CIE, 2005). 
The domestic market is served by four primary packers and marketers (Capilano, Beechworth, Leabrooks and Wescobee), a large number of small honey producers selling direct to the public, and the generic brands which are sold by the three leading supermarkets. The primary distribution channel for branded products is through the supermarkets, which currently account for around 80\% of retail sales (CIE, 2005).

There are approximately 845 beekeepers with around 34,000 hives in Western Australia. However, the majority of beekeepers are amateurs with fewer than 50 hives, and some 150 commercial or semi-commercial beekeepers, who manage more than 100 beehives (Wescobee, 2009). The Western Australian beekeeping industry has access to the State's famous pristine forests and coastal wildflowers. This provides some unique floral resources resulting in the ability to produce honeys that are not found elsewhere in the world. In 2007/2008, Western Australia produced about 3,000 tonnes of honey, of which some $30 \%$ was exported.

The apiculture industry in Western Australia is committed to quality assurance, to ensure that the product is clean, safe and free from chemical contamination. In order to reduce risk, honey and other hive products are not permitted to enter Western Australia without appropriate treatment (Department of Agriculture and Food).

Even so, despite the many positive advantages possessed by the Western Australia honey industry, product sales for the category are static. Intense competition on the retail shelf is reducing the price for the consumer, but there is little evidence that this is resulting in any increase in the quantity of honey consumed. Consequently, this study was commissioned to identify the major consumers of honey, how honey is used in the household, what things consumers most liked or disliked about honey and the main variables consumers considered when purchasing honey in a retail store.

\section{Consumer Purchasing Behavior}

Honey is most commonly consumed in its unprocessed state, i.e. liquid, crystallized or in the comb. In these forms it is consumed primarily as food or incorporated as an ingredient in various food recipes. However, the traditional use of honey in food preparations has largely been substituted by sugar and more recently by various sugar syrups derived from starches and low carbohydrate, artificial sweeteners ( Krell, 1996) However, honey is also used as a therapeutic, medicinal or cosmetic agent. Honey has antibacterial and antimicrobial qualities which have been shown to be effective on Streptococcus faecalis and Shigella disenteria, organisms which are resistant to some 
antibiotics. The regular consumption of honey has been shown to reduce blood sugar, to increase the metabolism of blood alcohol and to have an anti-inflammatory effect (Scott-Lower, 1987). As a wound dressing, honey not only inhibits bacteria, but also provides an impermeable physical barrier between the wound and bacteria. Honey prevents wound dressings from sticking to the skin which has made it a common burn treatment (Krell, 1996). Cosmetically, honey can be mixed with other ingredients to make cosmetic creams, lotions and shampoos. Preparations containing honey have a positive, softening effect on the skin and hair (Scott-Lower, 1987).

Pocol and Marghitas (2008) consider that the use of honey stems largely from family traditions learned as a child, which create a strong foundation on which to build new uses as an adult. Honey is characterised as a complex food. Its preferred attributes are: sweet taste and a healthy alternative to sugar (in food and beverage). The only significant negative aspect of honey is the mess so often associated with its use as a spread. The tendency to crystallize does not appear to limit its use.

According to Webb (2005), consumers make choices between alternative food products to potentially solve a problem. The level of consumer decision making may be either a limited search decision or a habitual or routine decision. Limited search decisions involve a small amount of searching for a product, but the buyer is likely to settle for a substitute product if the preferred item is not available. A routine decision is made when the product is purchased on a regular basis. For most fast moving consumer goods (FMCGs), which includes food items, the decision will fall some where between a routine decision and/or a limited search decision.

Arvanitoyannis and Krystallis (2005) identified four main motivations for purchasing honey: (i) medical benefits; (ii) dietary quality, (iii) ethical character of honey; and (iv) lifestyle. Cluster analysis revealed three groups of consumers: the common consumers; the younger consumers who are indifferent towards honey; and the enthusiastic consumers, who were more willing to purchase organic honey. In Romania, Pocol and Marghitas (2008) also identified three segments based on very different attributes. Segment 1 valued the medical qualities of honey; Segment 2 valued the natural image of honey; and Segment 3 were most concerned with the sweetness of honey and the fact that it could be substituted for sugar in recipes. Murphy, Cowan, Henchion and O’Reilly (2000) identified three distinct segments in the Irish honey market, each with an "ideal” product. Segment 1 was not price sensitive and preferred honey from small 
scale producers. Segment 2 preferred light coloured honey and Segment 3 was price sensitive and preferred mass-produced honey.

Unnevehr and Gouzou's (1998) analysis of the US retail honey market indicated that consumers were willing to pay substantial premiums for honey based on form, container, brand and floral source. The highest price premiums were associated with unique monofloral sources, followed by other unusual, but less pure, floral sources. Swanson and Lewis (1991) similarly demonstrated that consumers were willing to pay for the unique characteristics of honey associated with particular floral sources.

Research by the NHB (2006) showed that honey buyers in the US were predominantly women. Of the households surveyed, $82 \%$ had honey in the home. However, those consumers with a higher household income were more likely to use honey. The typical US honey consumer only used honey one time a week. The typical non-user listed their main reason for not purchasing honey as being too sweet.

\section{Research Methodology}

The objective of this study was to identify the factors that were most influential in the consumers' decision to purchase honey in Western Australia. Data was collected in face-to-face interviews using a structured questionnaire. To ensure a random and representative sample was obtained, respondents were interviewed on different days, at different times of the day and at a number of different shopping precincts in the Perth metropolitan area. A percentage of surveys were completed on weekends and late night shopping days to ensure that those people who worked during the week were adequately captured. Candidates for the interview were randomly selected by asking every fourth person who passed the interviewer. If the respondent declined to answer the questionnaire, then the next person who passed would be interviewed and so on.

The questionnaire included both open-ended and closed-response questions. The questionnaire began by qualifying the respondent. This included determining if the respondent had the time to complete the survey, if they were personally involved in the decision to purchase fresh food in their household and if they had purchased honey in the last twelve months. Once the respondent was qualified, a series of questions followed regarding the respondents household consumption, their use of honey and the variables used in their decision to purchase honey. The last part of the questionnaire included several questions regarding the demographic and 
socioeconomic position of the respondents including age, gender, income, place of residence, household size and ethnicity.

A total of 645 respondents were interviewed. The survey was completed between March and May 2009. The data was encoded and loaded into SPSS 17.0 for analysis.

\section{Results}

\section{Respondents}

The majority of respondents were female (65\%). Most respondents (51\%) were aged between 18-34 years. A similar proportion of respondents were aged between 35-44 years (18\%) and 45-54 years (17\%). Respondents aged 55-64 years and over the age of 65 years each accounted for $7 \%$ of the respondents interviewed.

The majority of the respondents were born in Australia (61\%). For those respondents who were not born in Australia, the largest number of respondents came from Malaysia (20\%), the UK (16\%), Indonesia (10\%), Borneo/Brunei (7\%), China (7\%), Singapore (6\%), New Zealand (5\%), the USA (4\%) and India (3\%).

The majority of respondents (69\%) lived in a household with 1 to 3 other people.

Respondents were employed in 32 occupational groups including students (12\%), retirees/pensioners (7\%), farmers/pastoralists (4\%), teachers/teacher’s aides (4\%), managers/business managers (3\%), or were otherwise employed in a professional, trade or clerical capacity. The majority of respondents (75\%) had a combined household income of between AUD 30,001-150,000 per annum.

\section{Consumers Likes and Dislikes}

The most frequently cited responses for liking honey was that honey had a good taste/flavour (81\%), it was a healthy product that was good for you (14\%) and a natural product (11\%). Conversely, the most frequently cited reason for not liking honey was because it was sticky/messy (69\%). For some 9\% of respondents, honey was too sweet, it was too difficult to get out of the jar/bottle (8\%), it was too runny (5\%) or it had crystallised (3\%).

\section{Consumers Use of Honey}

For the $90 \%$ of respondents who could recall the last time they purchased honey, some $47 \%$ had purchased honey within the last month. The supermarket was the primary place of purchase (69\%). On the last occasion that they purchased honey, one 
half of the respondents purchased honey in a plastic squeeze bottle. Some $17 \%$ of respondents purchased honey in a $500 \mathrm{ml}$ glass jar, 16\% in a $375 \mathrm{ml}$ glass jar and 13\% in a $1 \mathrm{~kg}$ tub. For the honey that the respondent had most recently purchased, most respondents (63\%) believed that it would last for one to three months, while $28 \%$ of the respondents believed that it would last for over 4 months.

Respondents ranked themselves as the major consumer of honey in the household, while children and the spouse were the other two groups most likely to consume honey in the household.

Within the household, honey was most often eaten as a spread (68\%). The other most popular means for consuming honey were on cereals/porridge (49\%), as a marinade (32\%), in drinks (32\%) or in cakes/cookies (21\%). Honey was very rarely consumed on its own (Table 1).

Table 1: Ways in Which Honey was Eaten in the Respondents Household

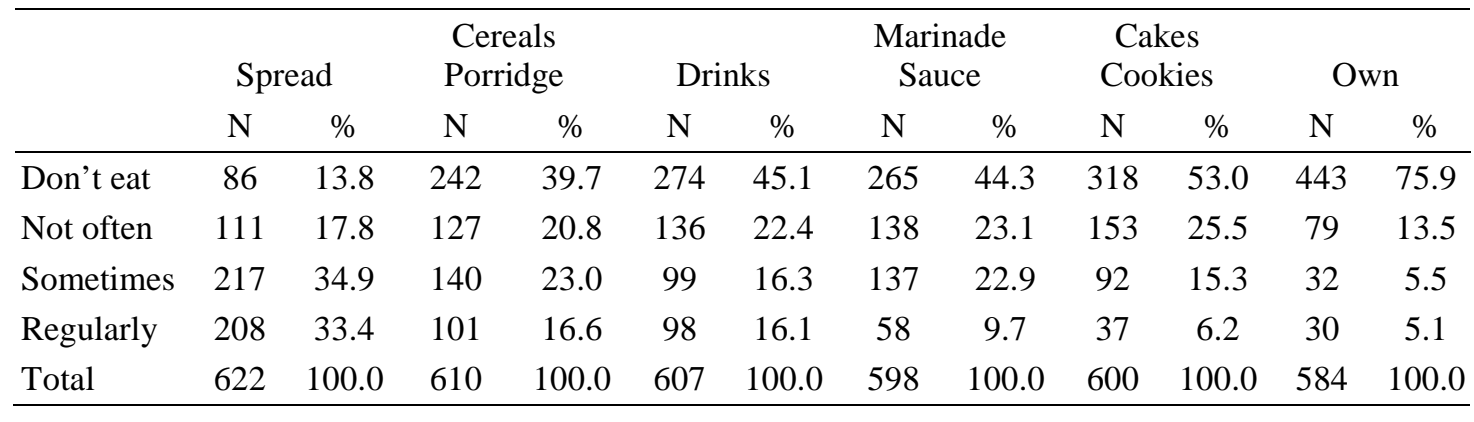

Despite the many alternative uses of honey (Table 2), it was evident that less than $9 \%$ of the respondents regularly used honey as a health supplement and only $5 \%$ of the respondents regularly used honey as either an energy additive or to treat medical conditions (Table 3).

In order to potentially segment the market on the basis of consumption, cluster analysis was conducted. After conducting hierarchical cluster analysis, it was apparent that a 5 cluster solution was appropriate. After running the K-means cluster algorithm, differences between the cluster members became apparent (Table 4).

Cluster 1 was a multi-purpose group (15\%), which used honey regularly as a spread, in drinks, on cereals/porridge and sometimes as a marinade/sauce and in cakes/cookies. Cluster 2 was a cooking group (15\%), which was typified by those respondents who used honey more regularly as a marinade and in cakes/cookies. Cluster 3 was a beverage group (19\%), which was typified by those who regularly used honey as a beverage. The fourth cluster (23\%) was a breakfast group, which was 
typified by those respondents who used honey as a spread and on cereals/porridge.

The last cluster (27\%) was the traditional group, who only used honey as a spread.

Table 2: Other Uses of Honey

\begin{tabular}{|c|c|c|c|c|c|}
\hline & Use1 & Use 2 & Use 3 & $\mathrm{~N}$ & $\%$ \\
\hline Sooths sore throats/good for dry throats & 55 & 8 & 1 & 64 & 26.6 \\
\hline Replacement for sugar & 31 & 9 & 2 & 42 & 17.4 \\
\hline Natural product/natural sugar & 24 & 11 & 1 & 36 & 14.9 \\
\hline Energy supplement & 25 & 6 & 1 & 32 & 13.3 \\
\hline General health/healthy lifestyle & 20 & 2 & 5 & 27 & 11.2 \\
\hline Good for colds/flu/clears chest & 20 & 1 & 3 & 24 & 10.0 \\
\hline Healing properties & 10 & 10 & 1 & 21 & 8.7 \\
\hline Digestion/alleviates upset stomachs & 4 & 12 & 2 & 18 & 7.5 \\
\hline Enhances immune system & 14 & 1 & & 15 & 6.2 \\
\hline Anti bacterial/antiseptic/anti microbial & 7 & 6 & & 13 & 5.4 \\
\hline Good all round product & 8 & 1 & 1 & 10 & 4.1 \\
\hline Skin mask/skin care & 3 & 1 & 2 & 6 & 2.5 \\
\hline Nutritional value/lemon drinks & 3 & 2 & & 5 & 2.1 \\
\hline Low fat & 2 & 3 & & 5 & 2.1 \\
\hline No preservatives/no additives & 1 & 2 & & 4 & 1.7 \\
\hline Treating allergies & 3 & & & 3 & 1.2 \\
\hline Sooths/relaxes/calms & 2 & & 1 & 3 & 1.2 \\
\hline Improves/enhances virility & 3 & & & 3 & 1.2 \\
\hline Draws out splinters & & 3 & & 3 & 1.2 \\
\hline Health food & 3 & & & 3 & 1.2 \\
\hline Cures/alleviates upsets stomachs & & 2 & & 2 & 0.8 \\
\hline Anti microbial & & 2 & & 2 & 0.8 \\
\hline Balances blood sugar & 1 & & 1 & 2 & 0.8 \\
\hline Hair treatment & 1 & & 1 & 2 & 0.8 \\
\hline Arthritis & 1 & & & 1 & 0.4 \\
\hline Heals cracked skin & & 1 & & 1 & 0.4 \\
\hline Respondents & 241 & & & & \\
\hline
\end{tabular}

Table 3: Other Ways in which Respondents Used Honey

\begin{tabular}{|c|c|c|c|c|c|c|c|c|c|c|c|c|c|c|}
\hline & \multicolumn{2}{|c|}{$\begin{array}{c}\text { Health } \\
\text { Supplement }\end{array}$} & \multicolumn{2}{|c|}{$\begin{array}{l}\text { Energy } \\
\text { Additive }\end{array}$} & \multicolumn{2}{|c|}{$\begin{array}{l}\text { Medical } \\
\text { Conditions }\end{array}$} & \multicolumn{2}{|c|}{ Skin Care } & \multicolumn{2}{|c|}{ Antiseptic } & \multicolumn{2}{|c|}{$\begin{array}{c}\text { Therapeutic } \\
\text { Agent }\end{array}$} & \multicolumn{2}{|c|}{ Hair Care } \\
\hline & $\mathrm{N}$ & $\%$ & $\mathrm{~N}$ & $\%$ & $\mathrm{~N}$ & $\%$ & $\mathrm{~N}$ & $\%$ & $\mathrm{~N}$ & $\%$ & $\mathrm{~N}$ & $\%$ & $\mathrm{~N}$ & $\%$ \\
\hline Don't use & 405 & 66.2 & 449 & 74.3 & 483 & 79.8 & 521 & 86.0 & 519 & 85.9 & 532 & 89.0 & 564 & 94.3 \\
\hline Not often & 79 & 12.9 & 78 & 12.9 & 56 & 9.3 & 38 & 6.3 & 51 & 8.4 & 33 & 5.5 & 16 & 2.7 \\
\hline Sometimes & 76 & 12.4 & 48 & 7.9 & 36 & 6.0 & 26 & 4.3 & 23 & 3.8 & 11 & 1.8 & 12 & 2.0 \\
\hline Regularly & 52 & 8.5 & 29 & 4.8 & 30 & 5.0 & 21 & 3.5 & 11 & 1.8 & 22 & 3.7 & 6 & 1.0 \\
\hline Total & 612 & 100.0 & 604 & 100.0 & 605 & 100.0 & 606 & 100.0 & 6041 & 100.0 & 598 & 100.0 & 598 & 100.0 \\
\hline
\end{tabular}


Table 4: Cluster Variates of the Ways in which Honey is Eaten

\begin{tabular}{lcccccr}
\hline & \multicolumn{7}{c}{ Cluster } & & Sig \\
\hline Spread & 1 & 2 & 3 & 4 & 5 & .000 \\
Cereals/ Porridge & 3.22 & 2.87 & 1.95 & 3.02 & 3.16 & .000 \\
Marinade/ Sauce & 3.05 & 1.65 & 1.35 & 3.40 & 1.28 & .000 \\
Cakes/ Cookies & 2.69 & 3.16 & 1.76 & 1.66 & 1.15 & .000 \\
Drinks & 2.53 & 2.03 & 1.56 & 1.48 & 1.30 & .000 \\
Own & 3.11 & 1.29 & 3.25 & 1.44 & 1.28 & .000 \\
\hline Number of cases & 2.20 & 1.16 & 1.32 & 1.21 & 1.19 & \\
\hline
\end{tabular}

Where 1 is "not at all"; 2 is "not often"; 3 is "sometimes" and 4 is "regularly"

Not unexpectedly, female respondents were more likely than males to use honey on cereals/porridge, in cakes/cookies, for hair care, for skin care and as an antiseptic and a therapeutic agent. On the other hand, males were more likely to use honey as a health supplement and energy additive.

Female respondents were also more likely to use honey to sooth sore throats, to treat coughs and colds, to sooth and clear chest colds, to aid digestion and to alleviate upset stomachs. Male respondents were more likely to use honey to enhance the immune system and for its antibacterial properties.

There were significant differences between ethnicity and the way in which honey was used. Having reclassified respondents into two groups on the basis of their country of birth, Anglo Saxons were more likely to use honey as a spread (3.06) and on cereals and porridge (2.25) than Asians (Table 5).

Table 5: Independent Samples T-test for Honey Use and Ethnicity

\begin{tabular}{llccc}
\hline & \multicolumn{1}{c}{ Ethnicity } & N & Mean & Sig \\
\hline \multirow{2}{*}{ Spread } & Anglo Saxon & 470 & 3.06 & .000 \\
& Asian & 129 & 2.16 & \\
Cereal & Anglo Saxon & 459 & 2.25 & .000 \\
& Asian & 128 & 1.76 & \\
Marinade & Anglo Saxon & 447 & 1.92 & .012 \\
& Asian & 130 & 2.18 & \\
Cakes/cookies & Anglo Saxon & 451 & 1.74 & .696 \\
& Asian & 127 & 1.71 & \\
Drinks & Anglo Saxon & 450 & 1.83 & .000 \\
& Asian & 133 & 2.61 & \\
Own & Anglo Saxon & 432 & 1.29 & .000 \\
& Asian & 132 & 1.68 & \\
\hline
\end{tabular}

Where 1 is "not at all”; 2 is "not often"; 3 is "sometimes" and 4 is "regularly" 
Conversely, Asians were more likely to consume honey in marinades (2.18), in drinks (2.61) and on its own (1.68). There was no difference between the ethnic groups in relation to the frequency with which honey might be used in cakes or cookies.

In exploring the alternative uses for honey, significant differences in ethnicity were once again observed. Asian respondents were significantly more likely than Anglo Saxons to use honey for skin care (1.42), as a health supplement (2.16), as an energy additive (1.86) and to treat medical conditions (1.69)(Table 6).

Table 6: Independent Samples T-test for Alternative Uses of Honey and Ethnicity

\begin{tabular}{llccc}
\hline & \multicolumn{1}{c}{ Ethnicity } & N & Mean & Sig \\
\hline \multirow{2}{*}{ Hair care } & Anglo Saxon & 452 & 1.08 & .197 \\
& Asian & 124 & 1.15 & \\
Skin care & Anglo Saxon & 457 & 1.19 & .007 \\
\multirow{4}{*}{ Antiseptic } & Asian & 126 & 1.42 & \\
& Anglo Saxon & 457 & 1.22 & .118 \\
Health supplement & Asian & 124 & 1.14 & \\
& Anglo Saxon & 457 & 1.44 & .000 \\
Energy additive & Asian & 130 & 2.16 & \\
& Anglo Saxon & 455 & 1.29 & .000 \\
Medical conditions & Asian & 126 & 1.86 & \\
Therapeutic agent & Asian & 457 & 1.25 & .000 \\
& Anglo Saxon & 125 & 1.69 & \\
& Asian & 455 & 1.17 & .203 \\
\hline
\end{tabular}

Where 1 is "not at all”; 2 is “not often"; 3 is "sometimes” and 4 is "regularly"

\section{Purchasing Criteria}

In making their decision to purchase honey from a retail store, low price/low cost/cheap/affordable (68\%) was the most frequently cited variable, followed by taste/flavour (14\%), quality/consistency (12\%) and convenience/packaging (11\%). However, when asked to rate the importance of the attributes respondents most often used in their decision to purchase honey from a retail store, taste/flavour (5.22) was the singly most important variable. Right size (4.94), reputation of the brand (4.90) and convenient packaging (4.68) were of moderate importance, while the less important variables were value for money (3.83), colour (3.69), label or brand (3.53) and variety (3.21)(Table 7). 
Table 7: Importance of Purchasing Decision Variables

\begin{tabular}{lcc}
\hline & Mean & Std. Deviation \\
\hline Taste/flavour & 5.22 & 1.19 \\
Right sized product & 4.94 & 1.32 \\
Reputation of the brand & 4.90 & 1.37 \\
Convenient packaging & 4.68 & 1.40 \\
Australian made & 4.43 & 1.69 \\
Health benefits & 4.35 & 1.45 \\
Price & 4.29 & 1.61 \\
WA made & 4.19 & 1.78 \\
Favourable prior purchase & 4.07 & 1.63 \\
Value for money & 3.83 & 1.67 \\
Colour & 3.69 & 1.54 \\
Label or brand & 3.53 & 1.64 \\
Variety & 3.21 & 1.53 \\
\hline
\end{tabular}

Where 1 is "not at all important" and 6 is "very important"

However, given that honey is a relatively low involvement product, it is unlikely that consumers will use all 13 variables in their decision to purchase. Principal component analysis is a multivariate data analysis technique which analyses covariance among a set of variables, reducing the number of variables to a more manageable set of attributes. Principal component analysis (with Kaiser normalisation and varimax rotation) was able to extract 3 components which collectively explained $61 \%$ of the variance (Table 8$)$.

Table 8: Principal Component Analysis

\begin{tabular}{lccc}
\hline & \multicolumn{3}{c}{ Component } \\
& 1 & 2 & 3 \\
\hline Reputation & .788 & & \\
Label & .715 & & \\
Colour & .685 & & \\
Prior Purchase & .597 & & \\
Health Benefits & .579 & & \\
Taste & .413 & & \\
Aus Made & & .930 & \\
WA Made & & .926 & \\
Value & & & .881 \\
Price & & & .880 \\
& & & \\
Eigen value & & & \\
Percent variance & 3.191 & 1.707 & 1.258 \\
Cumulative variance & 31.941 & 17.707 & 12.57 \\
Cronbach' alpha & 31.941 & 49.012 & 61.589 \\
Components mean item score & .737 & .904 & .778 \\
\hline
\end{tabular}


Component One (brand recognition) was comprised of brand reputation, label, colour, prior purchase, health benefits and taste. Component Two (product origin) was comprised of two variables: product of Australia and product of Western Australia. Component Three (value), which had the highest mean score and was the most important component, included competitive price and value.

Respondents from Asia were observed to rank the importance of both value (5.12) and brand recognition (4.31) significantly higher than Anglo Saxons (Table 9).

Table 9: Principal Components by Ethnicity

\begin{tabular}{llccc}
\hline & \multicolumn{1}{c}{ Ethnicity } & $\mathrm{N}$ & Mean & Sig \\
\hline \multirow{2}{*}{ Brand recognition } & Anglo Saxon & 480 & 4.07 & .023 \\
& Asian & 136 & 4.31 & \\
\multirow{3}{*}{ Product origin } & Anglo Saxon & 477 & 4.60 & .000 \\
& Asian & 135 & 3.24 & \\
Value & Anglo Saxon & 477 & 4.87 & .037 \\
& Asian & 136 & 5.12 & \\
\hline
\end{tabular}

Where 1 is "not at all important" and 6 is "very important"

Conversely, Anglo Saxons placed significantly more importance on the product origin (4.60).

\section{Discussion}

As expected, results show that females continue to do the majority of household shopping. As the primary decision makers, females determine what food is purchased and available to the household to consume. With regard to honey, it was evident that consumers only purchased the equivalent of 4-6 jars of honey per year. This correlates well with the ABS statistics which indicate that the apparent consumption of honey in Australia is around $0.5 \mathrm{~kg}$ per capita (ABS 2000).

While good taste/flavour were the attributes that respondents were most liked about honey, that attribute which was the least liked was the mess so often associated with the use of the product. For this reason, most respondents preferred to purchase honey in soft plastic squeeze bottles as it was easier to use, there was less mess, it was more clean, more convenient and the honey stayed fresh for longer.

In Western Australia, honey is still most often used as a spread or as a sweetener on cereals or porridge. Similar uses of honey are reported by Bainbridge (2007) and 
Goldschmidt (2009). However, as increasing numbers of Asian immigrants choose to settle in Western Australia, the consumption of honey as a drink and as a marinade is expected to increase. Asians are also more likely to use honey as a health supplement, an energy additive and to treat pre-existing medical conditions.

Although the health giving properties, the antiseptic and antibacterial properties of honey are well documented, somewhat surprisingly, there is little evidence of any consumer research in Asia with regard to the potential uses of honey and the attributes consumers may potentially use in their decision to purchase honey from a retail store. Price it seems is the most important factor, but Anglo Saxons are observed to place more importance on the product origin. With the more widespread occurrence of Colony Collapse Disorder, which has decimated bee populations in Europe and the US, domestic shortfalls are being met by increasing imports. In the wake of an alarming increase in the number of international food safety incidents, consumers are expected to pay greater attention to the product label and to the country-of-origin. Irrespective, as the power and influence of the supermarkets continues to increase and as more private brands emerge on the retail shelf, it will become more difficult for the independent producers and manufacturers to establish any long-term brand loyalty. As consumers only purchase honey 4-6 times per year, assuming the honey is appropriately packaged, the decision to purchase in-store is most likely to be made on the basis of price.

\section{References}

AAFRD (2005). Commercial honey industry. Alberta Agriculture, Food and Rural Development, Retrieved 16 May, 2009 from http://www1.agric.gov.ab.ca/ \$department/ deptdocs.nsf/all/agdex2743

Arvanitoyannis, I. and Krystallis, A. (2006). An empirical examination of the determinants of honey consumption in Romania. International Journal of Food Science and Technology, 41, 1164-1176.

Australian Bureau of Statistics (2000). Apparent consumption of foodstuffs 1998-99.

Bainbridge, J. (2007). Healthy honey sustains market. Marketing, June 13, 30.

Centre for International Economics (CIE)(2005). Future directions for the Australian honeybee industry. Retrieved: 12 June, 2009, from http://www.thecie.com.au /content/publications/CIE-future_directions_australian_honeybee.pdf 
Department of Agriculture and Food, Western Australia. When honey's not so sweet? Retrieved 1 June 2009, from http://www.agric.wa.gov.au/pls/portal30/docs/ FOLDER/IKMP/PW/Q/QHONEY_DLSHEET.PDF

Goldschmidt, B. (2009). Sweet sensation. Progressive Grocer, 88(2), 62

Krell, R. (1996). Value-added products from beekeeping. FAO Agricultural Services Bulletin No. 124. Food and Agriculture Organization of the United Nations. Rome. http://www.fao.org/docrep/w0076E/w0076E00.htm

Murphy, M., Cowan, C., Henchion, M. and O’Reilly, S. (2000). Irish consumer preference for honey: a conjoint approach, British Food Journal, 102(8), 585-597.

National Honey Board (2006). Honey attitude and usage study final results - 2006. National Honey Board (US).

National Honey Board. Honey and wellness. Retrieved 1 June 2009, from http:// www.honey.com/downloads/HoneyAndWellness.pdf

Pocol, C. and Marghitas, L. (2008). A comparison between the segmentation of honey market in Romania and Ireland, Bulletin UAVSM 65(2), 279-282

Pocol, C. and Marghitas, L. (2008). Qualitative exploration of honey among consumer segments by using the focus group method. Bulletin UAVSM, 65(2), 460

Scott-Lower, E. (1987). Honey- its properties and uses - Part I. British Food Journal, July/August: 60-62.

Scott-Lower, E. (1987). Honey- its properties and uses - Part II. British Food Journal, July/August: 84-86

Swanson, R.B. and Lewis, C.E. (1991). Premiums for honey characteristics. Food Quality and Preference, 3(4), 215-221.

Unnevehr, L.J. and Gouzou, F.C. (1998). Retail Premiums for Honey Characteristics. Agribusiness, 14(1), 49-54.

Webb, K. (2005). Consumer behaviour. McGraw-Hill.

Wescobee (2009). Apiculture. Retrieved 12 June 2009, from http://www.wescobee.com/Apiculture.html 